\title{
A/T/N: An unbiased descriptive classification scheme for Alzheimer disease biomarkers
} OPEN

Clifford R. Jack, Jr., MD David A. Bennett, MD Kaj Blennow, MD, PhD Maria C. Carrillo, $\mathrm{PhD}$ Howard H. Feldman, MD

Giovanni B. Frisoni, MD Harald Hampel, MD, $\mathrm{PhD}$

William J. Jagust, MD Keith A. Johnson, MD

David S. Knopman, MD

Ronald C. Petersen, MD, $\mathrm{PhD}$

Philip Scheltens, MD, $\mathrm{PhD}$

Reisa A. Sperling, MD Bruno Dubois, MD, PhD

Correspondence to

Dr. Jack:

jack.clifford@mayo.edu

Editorial, page 456

\section{ABSTRACT}

Biomarkers have become an essential component of Alzheimer disease (AD) research and because of the pervasiveness of $A D$ pathology in the elderly, the same biomarkers are used in cognitive aging research. A number of current issues suggest that an unbiased descriptive classification scheme for these biomarkers would be useful. We propose the "A/T/N" system in which 7 major AD biomarkers are divided into 3 binary categories based on the nature of the pathophysiology that each measures. " $A$ " refers to the value of a $\beta$-amyloid biomarker (amyloid PET or CSF $\left.A \beta_{42}\right) ;$ " $T$," the value of a tau biomarker (CSF phospho tau, or tau PET); and " $N$," biomarkers of neurodegeneration or neuronal injury $\left(\left[{ }^{18} \mathrm{~F}\right]\right.$-fluorodeoxyglucose-PET, structural MRI, or CSF total tau). Each biomarker category is rated as positive or negative. An individual score might appear as $\mathrm{A}+/ \mathrm{T}+/ \mathrm{N}-$, or $\mathrm{A}+/ \mathrm{T}-/ \mathrm{N}-$, etc. The $\mathrm{A} / \mathrm{T} / \mathrm{N}$ system includes the new modality tau PET. It is agnostic to the temporal ordering of mechanisms underlying $A D$ pathogenesis. It includes all individuals in any population regardless of the mix of biomarker findings and therefore is suited to population studies of cognitive aging. It does not specify disease labels and thus is not a diagnostic classification system. It is a descriptive system for categorizing multidomain biomarker findings at the individual person level in a format that is easy to understand and use. Given the present lack of consensus among AD specialists on terminology across the clinically normal to dementia spectrum, a biomarker classification scheme will have broadest acceptance if it is independent from any one clinically defined diagnostic scheme. Neurology ${ }^{\circledR}$ 2016;87:539-547

\section{GLOSSARY}

$\mathbf{A} \boldsymbol{\beta}=\boldsymbol{\beta}$-amyloid; $\mathbf{A D}=$ Alzheimer disease; $\mathbf{F D G}=\left[{ }^{18} \mathrm{~F}\right]$-fluorodeoxyglucose; $\mathbf{I W G}=$ International Working Group; $\mathbf{M C l}=$ mild cognitive impairment; NIA-AA = National Institute on Aging-Alzheimer's Association; $\mathbf{p}$-tau = phosphorylated tau; SNAP = suspected non-Alzheimer pathophysiology; t-tau = total tau.

By providing measures of relevant pathophysiology in living persons, biomarkers have become increasingly important to understanding the biology of Alzheimer disease (AD). Biomarkers are also used in all modern research diagnostic criteria across the $\mathrm{AD}$ clinical spectrum, ${ }^{1-6}$ in therapeutic trials, and by regulatory agencies. ${ }^{7}$ Because $\mathrm{AD}$ pathology is so frequent in the elderly, $\mathrm{AD}$ biomarkers are also commonly used in cognitive aging research. However, several current issues suggest that a different approach to biomarkers used in $\mathrm{AD}$ research might be useful.

First, available evidence points to recently developed tau PET tracers as useful measures of neurofibrillary tangles in $\mathrm{AD}$, while utility in non-AD tauopathies has not yet been clarified. ${ }^{8,9}$ Elevated tau PET tracer signal, particularly in neocortical regions, is highly associated with the

From the Departments of Radiology (C.R.J.) and Neurology (D.S.K., R.C.P.), Mayo Clinic, Rochester, MN; Rush Alzheimer's Disease Center (D.A.B.), Rush University Medical Center, Chicago, IL; Clinical Neurochemistry Lab (K.B.), Department of Neuroscience and Physiology, University of Gothenburg, Mölndal Hospital, Sahlgrenska University Hospital, Mölndal, Sweden; Alzheimer's Association (M.C.C.), Chicago, IL; Division of Neurology (H.H.F.), UBC Hospital Clinic for Alzheimer's Disease and Related Disorders, University of British Columbia, Vancouver, Canada; Memory Clinic (G.B.F.), University Hospitals and University of Geneva, Switzerland; IRCCS Fatebenefratelli (G.B.F.), The National Centre for Alzheimer's Disease, Brescia, Italy; Sorbonne Universités (H.H.), Université Pierre et Marie Curie, Paris; Institut de la Mémoire et de la Maladie d'Alzheimer (IM2A) and Institut du Cerveau et de la Moelle épinière (ICM) (H.H.), Département de Neurologie, Hôpital de la Pitié-Salpétrière, Paris, France; Helen Wills Neuroscience Institute (W.J.J.), University of California, Berkeley; Departments of Radiology and Neurology (K.A.J.), Massachusetts General Hospital, Harvard Medical School, Boston; Alzheimer Center and Department of Neurology (P.S.), Vrije Universiteit Amsterdam, the Netherlands; Center for Alzheimer Research and Treatment (R.A.S.), Brigham and Women's Hospital and Massachusetts General Hospital, Harvard Medical School, Boston; Centre des Maladies Cognitives et Comportementales (B.D.), Institut du Cerveau et de la Moelle épinière, Paris; and Université Pierre et Marie Curie-Paris 6 (B.D.), AP-HP, Hôpital de la Salpêtrière, Paris, France. Go to Neurology.org for full disclosures. Funding information and disclosures deemed relevant by the authors, if any, are provided at the end of the article. The Article Processing Charge was paid by the authors.

This is an open access article distributed under the terms of the Creative Commons Attribution-NonCommercial-NoDerivatives License 4.0 (CC BY-NC-ND), which permits downloading and sharing the work provided it is properly cited. The work cannot be changed in any way or used commercially. 
presence of positive amyloid PET scans as would be expected in a ligand that binds to the tau deposits in AD. ${ }^{10,11}$ Tau PET ligand binding correlates well with clinical impairment in individuals who lie along the AD clinical spectrum. ${ }^{10,11}$ When easily characterized off-target and nonspecific binding is accounted for, the topographic patterns of ligand uptake match quite well what is expected from Braak staging of neurofibrillary tangles. ${ }^{12}$ However, because of its recent introduction, tau PET is not yet integrated into any current $\mathrm{AD}$ diagnostic schemes.

Second, many details of $\mathrm{AD}$ pathogenesis remain uncertain. ${ }^{13,14}$ One of the most contentious issues, and one of the oldest, is which proteinopathy "causes" the disease in the elderly. Some propose that $\mathrm{AD}$ pathogenesis follows a specific cause and effect order of events, where $\beta$-amyloidosis potentiates the spread of tauopathy, tauopathy is associated with neurodegeneration, which is the immediate cause of clinical symptoms. ${ }^{15}$ Others argue for different, less $\beta$-amyloid $(A \beta)$ centric pathways to clinically symptomatic $\mathrm{AD} .{ }^{13,14,16}$ Interdependent pathways have also been proposed. ${ }^{17} \mathrm{~A}$ biomarker classification system will have the broadest use if it makes no assumptions about temporal ordering of biomarkers or their putative causal relationships.

Third, current biomarker classification systems are linked to disease or syndromic labels and are based on consensus diagnostic criteria rather than certainty of disease pathogenesis. The 2 major such diagnostic schema are those of the International Working Group (IWG), ${ }^{1,18}$ which first proposed the use of a common biomarker algorithm for all clinical stages of the disease, and the National Institute on AgingAlzheimer's Association (NIA-AA). ${ }^{3-6}$ Although there are areas of agreement, important disagreements exist concerning staging, nomenclature, and interpretations of biomarker findings. We recognize that associating biomarkers with clinical findings is important. However, given the confusion that has arisen over the use of competing definitions of clinical impairment in the $\mathrm{AD}$ spectrum, ${ }^{19}$ a biomarker classification scheme will have broadest acceptance if it is independent from any one clinically operationalized diagnostic scheme. The biomarker classification scheme we propose is applicable across all clinical diagnostic states, and is thus independent of cognitive status.

Fourth, the prevalence of $\mathrm{AD}$, non- $\mathrm{AD}$, and mixed brain pathologies increases with age in both individuals who are clinically impaired and those nonimpaired. ${ }^{20}$ To be an effective tool in cognitive aging research, a biomarker classification system must include all possible biomarker profiles and all individuals in the population. For example, classification schemes that require $A \beta$ positivity do not classify individuals who are $A \beta$ negative but positive on tau or neurodegenerative biomarkers, yet the latter biomarker profile is common. ${ }^{21}$

The objective of this report is to propose an unbiased descriptive classification scheme for biomarkers commonly used in $\mathrm{AD}$ research that addresses each of these 4 issues.

AD BIOMARKERS We propose that the major biomarkers used in $\mathrm{AD}$ research can be divided into 3 binary categories based on the nature of the underlying pathophysiology each measures. Biomarkers of fibrillary $A \beta$ deposition are high ligand retention on amyloid PET ${ }^{22}$ or low CSF A $\beta_{42} \cdot{ }^{23-25}$ Biomarkers of tau pathology (neurofibrillary tangles) are elevated CSF phosphorylated tau (p-tau) and tau PET. ${ }^{24,26}$ Biomarkers of AD-like neurodegeneration or neuronal injury are CSF total tau (t-tau), $\left[{ }^{18} \mathrm{~F}\right]$ fluorodeoxyglucose (FDG)-PET hypometabolism, and atrophy on structural MRI in regions characteristic of $\mathrm{AD}^{27}$

CSF biomarkers report a single absolute value reflecting degree of abnormality but that does not indicate topographic extent of pathology. In contrast, imaging biomarkers contain information about both the severity and topographic extent of the abnormality. Typical AD (i.e., amnestic multidomain dementia) is associated with a characteristic topographic pattern of FDG-PET hypometabolism that appears earliest and most severely in the medial parietal and lateral temporal-parietal isocortex (figure 1A). ${ }^{28}$ Typical AD likewise is associated with a pattern of atrophy on MRI that appears earliest and most severely in the medial temporal allocortex and the basal-lateral temporal isocortex (figure $1 \mathrm{C}$ ). ${ }^{15} \mathrm{~A} \beta$ deposition on PET does not seem to follow a sequential topographic progression through the isocortex (figure 1E). Available evidence indicates that in the typical AD spectrum, tau PET captures the topography of tau spread as described at autopsy by Braak $^{12}$ — medial temporal to basal and lateral temporal, then to other isocortical areas (figure 2). 

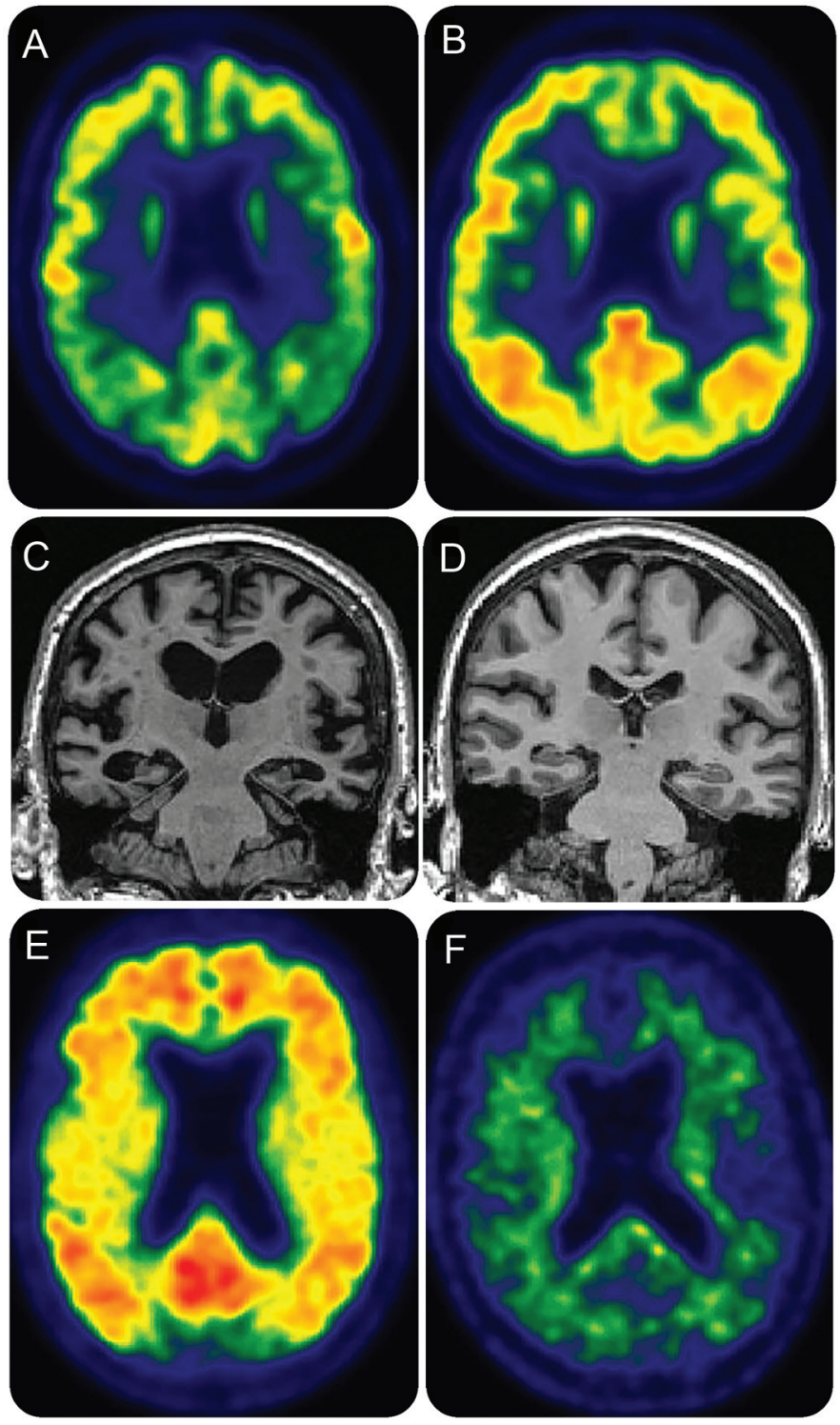

Individuals with AD dementia are clinically diagnosed participants in Mayo Alzheimer's Disease Research Center study while clinically normal individuals are participants in the Mayo Clinic Study of Aging. (A) FDG-PET of 75-year-old man with AD dementia. Hypometabolism in medial parietal and lateral temporal-parietal isocortex with relative preservation of frontal metabolism, which is characteristic of typical (multidomain amnestic) AD. (B) FDG-PET of clinically normal 71-year-old man. Uniform FDG uptake is present throughout the isocortex. (C) MRI of 71-year-old man with AD dementia. Atrophy is present in the medial temporal allocortex and the basal-lateral temporal isocortex, which is characteristic of typical (multidomain amnestic) AD. (D) MRI of clinically normal 71-year-old woman without atrophy. (E) Amyloid PET with Pittsburgh compound B of 71-year-old woman with AD dementia. Ligand uptake is seen throughout the isocortex. (F) Amyloid PET of clinically normal 93-year-old man showing no ligand uptake in the isocortex. $A D=$ Alzheimer disease; FDG $=\left[{ }^{18} \mathrm{~F}\right]$ fluorodeoxyglucose.

While each of the 7 commonly used core biomarkers is associated with $\mathrm{AD}$, they are not equally specific. Biomarkers of $\beta$-amyloidosis are specific for AD pathology. ${ }^{29-31}$ However, amyloid PET tracers do bind to $A \beta$ deposits in vessel walls, and increased tracer binding can be found following acute traumatic brain injury. ${ }^{32} \mathrm{CSF} \mathrm{A} \beta_{42}$ is decreased (i.e.,

abnormal) in some non-AD conditions such as HIV encephalitis ${ }^{33}$ and multiple system atrophy. ${ }^{34}$

Typical AD shows an increase in both t-tau and p-tau and a tight correlation between these biomarkers. ${ }^{35}$ Neither CSF t-tau nor p-tau shows any change in primary tauopathies such as frontotemporal dementia, progressive supranuclear palsy, or corticobasal degeneration. ${ }^{36,37}$ However, findings on CSF $\mathrm{t}$-tau and $\mathrm{p}$-tau diverge in conditions with acute brain damage. There is a marked temporary increase in t-tau with normal p-tau levels in traumatic brain injury and stroke that correlates with the severity of neuronal damage. ${ }^{38,39}$ It is the same for Creutzfeldt-Jakob disease, which shows a large increase in t-tau (reflecting rapid neurodegeneration) but normal p-tau since there are no neurofibrillary tangles in this condition. ${ }^{40,41}$ The CSF level of p-tau correlates with severity of tau pathology postmortem, ${ }^{30}$ and high p-tau has not been found in disorders other than $\mathrm{AD}$. Taken together, these data indicate that CSF $t$-tau reflects the intensity of neuronal degeneration in $\mathrm{AD}$ at a specific point, while p-tau seems more specific for the burden of AD-type tau pathology accumulated over time. ${ }^{42}$ Tau PET is being actively investigated, but initial data indicate that tau PET ligands have high binding affinity for paired helical filament tau in $\mathrm{AD}$ but have much weaker affinity in non- $\mathrm{AD}$ tauopathies, especially those with straight filament tangles. ${ }^{9}$

Atrophy and hypometabolism involving AD-like regions occur in a variety of disorders and are the least specific for $\mathrm{AD} .{ }^{43}$ Atrophy in the anterior/medial/basal temporal lobes occurs in a wide variety of pathologic conditions including $\mathrm{AD}$ but also cerebrovascular disease, epilepsy, anoxia, hippocampal sclerosis, TDP43-opathy, primary age-related tauopathy, ${ }^{44}$ chronic traumatic encephalopathy, argyrophilic grain disease, and non- $\mathrm{AD}$ primary tauopathies such as progressive supranuclear palsy and Pick disease. ${ }^{43}$ Temporoparietal hypometabolism can be found in non- $\mathrm{AD}$ conditions, such as corticobasal degeneration, primary progressive aphasia, ${ }^{45}$ and cerebrovascular disease. ${ }^{46}$ This nonspecificity is the explanation for the frequent and consistently observed finding of abnormal FDG-PET and structural MRI (and CSF t-tau) in non-AD conditionsa state that has been labeled suspected nonAlzheimer pathophysiology (SNAP). ${ }^{21}$

Interpreting biomarker data is confounded by the common coexistence of $\mathrm{AD}$ pathology, and therefore positive AD biomarkers, with other age-related pathologies. Multidomain amnestic dementia and mild cognitive impairment (MCI) are most commonly associated with multiple pathology, ${ }^{20}$ especially with advancing age.

THE A/T/N CLASSIFICATION SYSTEM In the proposed $\mathrm{A} / \mathrm{T} / \mathrm{N}$ classification system, the 7 major 

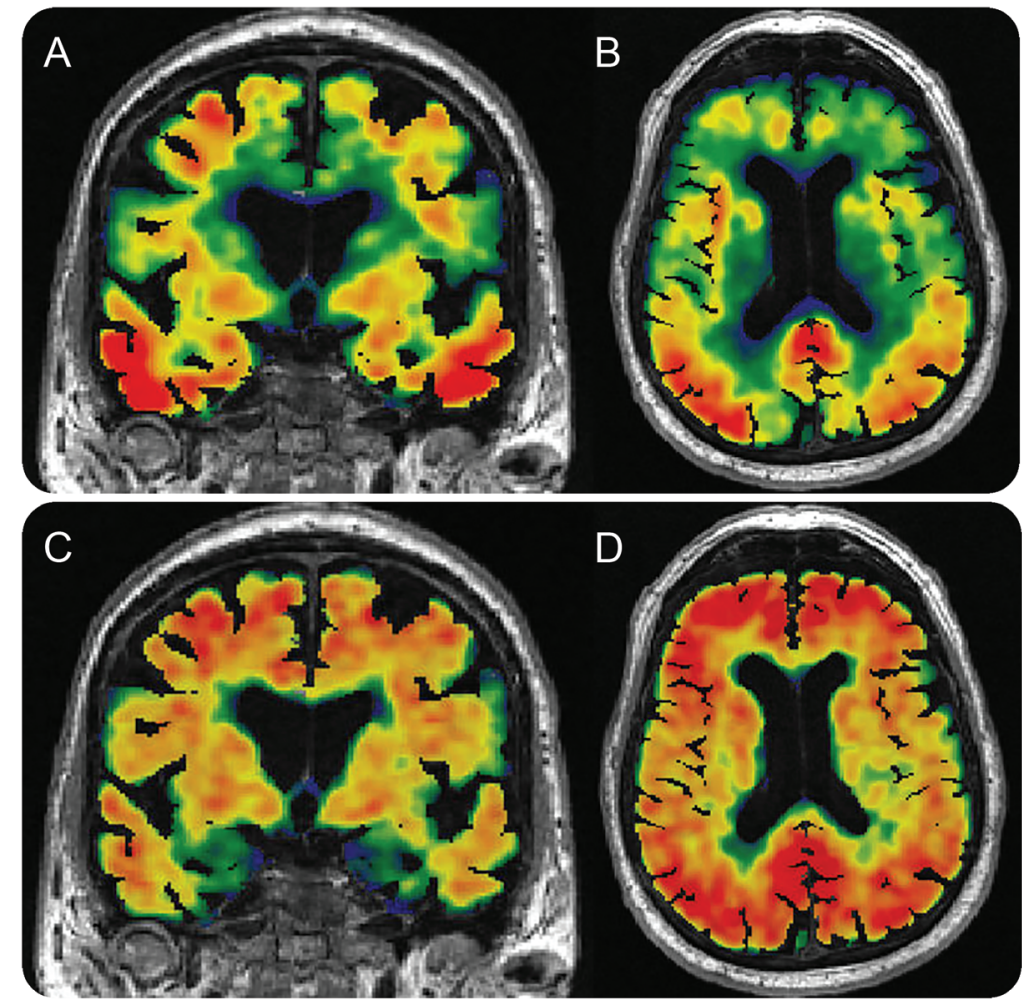

A 79-year-old man with a clinical diagnosis of $A D$ dementia. He is a participant in the Mayo Alzheimer's Disease Research Center study. (A, B) Coronal and axial tau PET images (AV1451) superimposed on MRI. (C, D) Coronal and axial Pittsburgh compound B PET images superimposed on MRI. The tau PET images (top) illustrate extensive tracer uptake in basal lateral temporal, parietal, and frontal isocortex with sparing of sensory motor and primary visual cortices. Off-target binding is seen in the basal ganglia, which is characteristic of this tracer. Although areas of spatial overlap between the tau and amyloid tracers are present, abundant amyloid tracer uptake is seen in the frontal lobes, but not with the tau tracer Conversely, abundant uptake is seen in the medial temporal lobes with the tau ligand but not with the amyloid ligand. $A D=$ Alzheimer disease.

$\mathrm{AD}$ biomarkers are divided into 3 binary classes. "A" refers to the value of an $A \beta$ biomarker (amyloid PET or CSF $\left.A \beta_{42}\right)$; " $T$," the value of a tau pathology biomarker (CSF p-tau or tau PET); and "N," a quantitative or topographic biomarker of neurodegeneration or neuronal injury (CSF t-tau, FDG-PET, or structural MRI).

The $\mathrm{A} / \mathrm{T} / \mathrm{N}$ classification system is related to the biomarker classification proposed in recent consensus diagnostic criteria. In both IWG and NIA-AA diagnostic criteria, $A$ refers to $A \beta$ (PET or CSF $A \beta$ ). Segregation of MRI and FDG-PET from CSF tau biomarkers was proposed by the IWG (2014), ${ }^{1}$ while in the NIA-AA criteria, MRI, FDG-PET, and CSF tau proteins were grouped together as biomarkers of neurodegeneration or neuronal injury. The rationale for grouping CSF tau, FDG-PET, and MRI atrophy into a single category in the NIA-AA criteria had strong support from numerous observations that the 3 behaved in a similar manner relative to clinical symptoms. More abnormal values in all 3 of these

POSITIVE/NEGATIVE OR NORMAL/ABNORMAL BIOMARKER CUTPOINTS Although every biomarker exists on a continuous scale, normal vs abnormal cutpoints exist in most disease categories to make diagnostic categorization of individuals practical and inform clinical decision-making. We recognize that cutpoints can be arbitrary, and many individuals will have biomarker values close to cutpoints. This is true for any disease and is not unique to biomarkers used in $\mathrm{AD}$ research. The presence of positive/negative cutpoints is not inherently problematic provided that values close to cutpoints are interpreted and used properly.

Amyloid biomarkers have been bimodally distributed in some research samples where participants are highly selected, ${ }^{49}$ while neurodegenerative biomarkers typically are not. This has led to the suggestion that cutpoints are not valid for neurodegenerative biomarkers. However, most physiologic measures 
are continuously, not bimodally, distributed-blood pressure, for example. ${ }^{50}$ This has not prevented medicine from identifying a cutpoint and designating those above hypertensive and those below normotensive. It seems illogical to treat $\mathrm{AD}$ differently from other diseases.

We emphasize that binary, $+/-$ categorization does not imply that individuals who fall below the cutpoint for a particular biomarker have no pathology in the brain. For example, an individual designated as A may well have amyloid plaques in the brain, but not at a sufficient level to cross the in vivo detection threshold of amyloid PET. Current biomarker readouts are not sensitive to low but perhaps biologically important levels of early pathology. ${ }^{51,52}$ The $+/-$ designation is a convenient shorthand to facilitate communication, ease of use, and understanding.

Several different approaches to selecting normal/ abnormal cutpoints in the continuous range of biomarker values exist. These include selecting values that best separate clinically normal individuals from those with dementia, values that have predictive power for future clinical decline, ${ }^{53}$ or using autopsied individuals with antemortem biomarker studies to guide selection of cutpoints. ${ }^{51,52}$ In laboratory medicine, the 95th percentile based on a healthy control population is commonly used. ${ }^{54} \mathrm{~A}$ popular approach has been to select cutpoints based on the (most normal) 10th percentile of values seen in typical $A D$ dementia. $^{21,55}$ Validating specific cutpoints will be an ongoing exercise for research groups working in each separate modality.

Experience labeling tau PET scans positive vs negative is limited at this point. Tauopathy confined to the medial temporal lobes with minimal or no neocortical $\beta$-amyloidosis is very common at autopsy and whether this should be regarded as AD or simply an aging phenomenon is controversial. ${ }^{12,13,44}$ One possible approach to categorizing tau PET is to label scans that have tracer uptake exceeding an analytically determined threshold in AD-like isocortical areas as "AD positive" (figure 2). Where tau is located and its topographic progression over time will be important. But for purposes of labeling a scan abnormal, we provisionally propose that a scan with tracer uptake confined to the medial temporal lobes would not be considered positive ${ }^{44}$ but a scan with uptake in $\mathrm{AD}$ like isocortical areas would. ${ }^{10}$

ALTERNATIVES TO POSITIVE/NEGATIVE SCORING OF BIOMARKERS Advantages of binary, $+/-$ categorization of each biomarker class include economy, conceptual clarity, and ease of use. Thus, we recommend binary, + / - categorization. Alternatives exist however and are briefly discussed for completeness. One alternative is to score the severity of each biomarker on a continuous or semicontinuous scale. An example of this, termed the centiloid scale, ${ }^{56}$ has been proposed for amyloid PET. The process requires empirically establishing reference values for the abnormal part of the distribution using individuals with $\mathrm{AD}$ dementia and for the normal part of the distribution using young, clinically normal individuals. Biomarker values are then scaled linearly from 0 (normal) to 100 (abnormal). The centiloid scale is related to but not identical to percentiles because centiloid values below 0 (i.e., below the mean for the normal group) and above 100 (i.e., above the mean for the abnormal group) are possible. An example of how this might appear is A80/T50/N20, where this individual ranks at the 80th centiloid for amyloid, 50th for tau, and 20th for neurodegeneration. This approach would require a 0 to 100 scale that was standardized across all biomarkers.

A second alternative to binary, $+/-$ biomarker scoring is topographic staging. This approach would only be applicable to imaging and might best apply to tau PET. Topographic tau PET staging would mirror pathologic Braak neurofibrillary tangle stage whereby individuals would be assigned to 1 of 3 stages based on anatomical locations of tracer uptake-i.e., stage 0 , limbic stage, isocortical stage. Since cortical atrophy on MRI closely mirrors Braak stage and tau density in imaging-autopsy correlation studies, ${ }^{57}$ and the topographic spread of atrophy within individuals over time also mirrors progressive Braak stages, this Braaklike topographic staging approach might be valid for MRI as well.

Generalizability of AD biomarker categorization is dependent on standardization and reproducibility of the measures. ${ }^{58}$

ATYPICAL AD, CEREBROVASCULAR DISEASE, AND EXPANSION OF THE CORE A/T/N SYSTEM The descriptions of FDG-PET, tau PET, and MRI topography outlined above reflect patterns of typical multidomain amnestic $\mathrm{AD}$ (figures 1 and 2). Because MRI, FDG, and tau PET topographic patterns map onto clinical phenotype, a different set of imaging signatures is needed to describe atypical variants of $\mathrm{AD}$. Although not detailed in the present report, the $\mathrm{A} / \mathrm{T} / \mathrm{N}$ system is equally applicable to atypical $\mathrm{AD}$ variants by modifying the topographic search pattern. For example, pattern recognition algorithms could easily be modified to recognize atrophy, hypometabolism, and tau PET deposition in the frontal, dominant temporal lobe, or posterior cortical regions for atypical $\mathrm{AD}$.

Our primary focus is the core $\mathrm{A} / \mathrm{T} / \mathrm{N}$ system, which addresses biomarkers of $\mathrm{AD}$; however, biomarkers of other proteinopathies could be added if/ when they become available. The category of synaptic dysfunction (S) may be a useful future addition and this might include FDG-PET, task-free functional 
Table 1 Clinically normal individuals

$\begin{array}{lll}\mathrm{A} / \mathrm{T} / \mathrm{N} \text { classification } & \begin{array}{l}\text { NIA-AA classification } \\ \text { preclinical AD }\end{array} & \text { 2014 IWG classification } \\ \mathrm{A}-/ \mathrm{T}-/ \mathrm{N}- & \text { Not defined } & \text { Not defined } \\ \mathrm{A}+/ \mathrm{T}-/ \mathrm{N}- & \text { Stage } 1 & \begin{array}{l}\text { Asymptomatic at risk of } \mathrm{AD} \text { (if } \mathrm{A}+ \\ \text { established by amyloid } \mathrm{PET} \text { ) }\end{array} \\ \mathrm{A}+/ \mathrm{T}+/ \mathrm{N}- & \text { Stage } 2 / 3 & \text { Asymptomatic at risk of } \mathrm{AD} \\ \mathrm{A}+/ \mathrm{T}-/ \mathrm{N}+ & \mathbf{a}^{\mathrm{a}} & \begin{array}{l}\text { Asymptomatic at risk of } \mathrm{AD} \text { (if } \mathrm{A}+ \\ \text { established by amyloid } \mathrm{PET} \text { ) }\end{array} \\ \mathrm{A}+/ \mathrm{T}+/ \mathrm{N}+ & \text { Asymptomatic at risk of } \mathrm{AD} \\ \mathrm{A}-/ \mathrm{T}+/ \mathrm{N}-{ }^{\mathrm{b}} & \text { Stage } 2 / 3 & \text { Not defined } \\ \mathrm{A}-/ \mathrm{T}-/ \mathrm{N}+{ }^{\mathrm{b}} & \text { Not defined } & \text { Not defined } \\ \mathrm{A}-/ \mathrm{T}+/ \mathrm{N}+{ }^{\mathrm{b}} & \text { Not defined } & \text { Not defined }\end{array}$

Abbreviations: $A D=$ Alzheimer disease; FDG $=\left[{ }^{18} \mathrm{~F}\right]-$ fluorodeoxyglucose; IWG = International Working Group; NIA-AA = National Institute on Aging-Alzheimer's Association.

${ }^{a}$ This combination was not addressed in NIA-AA preclinical AD criteria on the assumption that neurodegeneration on MRI and FDG-PET that is specifically attributable to AD was tau-related.

${ }^{\mathrm{b}}$ Described as SNAP (suspected non-Alzheimer pathophysiology) in several publications.

MRI, EEG, MEG (magnetoencephalography), as well as synapse-specific proteins in CSF. ${ }^{59}$ However, if neurodegeneration is defined as progressive loss and shrinkage of neurons and processes with a corresponding impairment in neuronal function, ${ }^{15}$ then synaptic dysfunction is subsumed within the category of neurodegeneration.

The core A/T/N system could also be supplemented by adding a cerebrovascular disease category. A limitation is the absence of an agreed on pathologic summary scoring system for cerebrovascular disease on which to base an imaging counterpart. Nonetheless, systems in which the MRI findings of ischemic cerebrovascular disease are combined to form a vascular (V) summary score have been described. ${ }^{60}$ The $\mathrm{A} /$ $\mathrm{T} / \mathrm{N}$ system would then be extended to A/T/N/V by compressing the vascular index into $\mathrm{V}+$ or $\mathrm{V}-$.

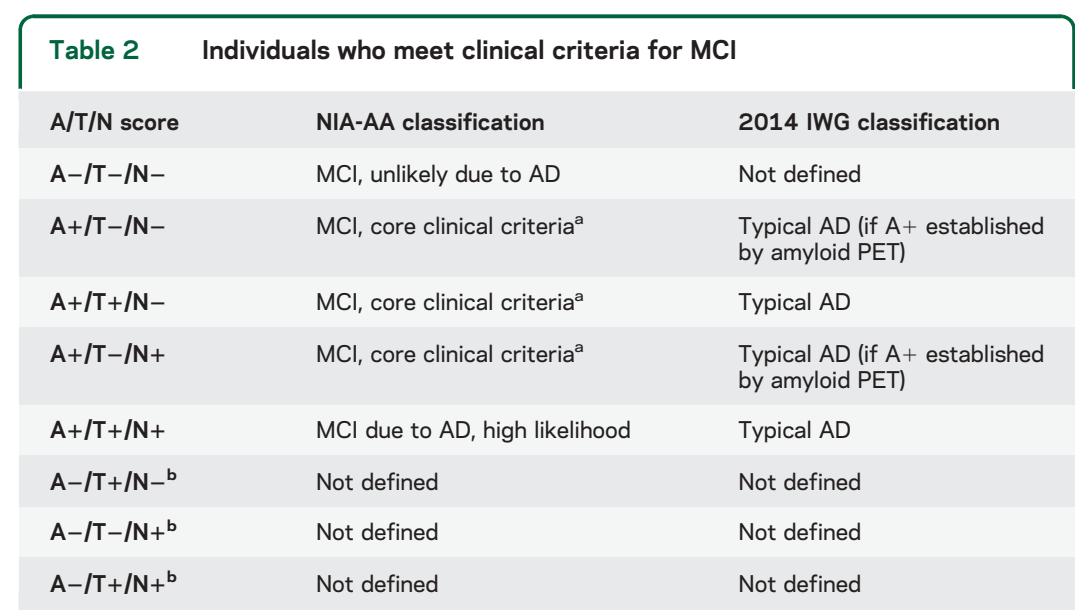

Abbreviations: $A D=$ Alzheimer disease; IWG $=$ International Working Group; $\mathrm{MCl}=$ mild cognitive impairment; NIA-AA = National Institute on Aging-Alzheimer's Association.

a In the event of conflicting results, biomarkers are regarded as "uninformative" and therefore do not alter the individual's diagnostic classification based on clinical assessment alone.

${ }^{\mathrm{b}}$ Described as MCI-SNAP (suspected non-Alzheimer pathophysiology) in several publications.
APPLICATION OF THE A/T/N SYSTEM IN COGNITIVE AGING AND DEMENTIA RESEARCH: $A / T / N / C$ The A/T/N system provides a common framework by which investigators can describe and communicate multidomain biomarker profiles at the individual person level. Application in cognitive aging and dementia research, however, will require the inclusion of clinical information about each individual. Clinical status (C) could be denoted in several possible ways resulting in A/T/N/C notation. Setting aside detailed syndromic descriptions, cognitive function can be thought of categorically or as a continuum. The cognitive/functional continuum could be divided into normal for age (n), mildly impaired $(\mathrm{m})$, or demented (d), resulting in designations of A/T/N/Cn, A/T/N/Cm, or A/T/N/Cd. The cognitive continuum could also be expressed as a continuous variable on a 0 (normal) to 100 (abnormal) scale; individuals are assigned values along this 0 to 100 scale.

\section{HOW DOES THE A/T/N SYSTEM RELATE TO} EXISTING AD CLINICAL CLASSIFICATION SYSTEMS? The IWG and NIA-AA criteria both integrate 5 biomarkers into the diagnostic classification process: CSF $A \beta_{42}$ and tau proteins, amyloid PET, FDG-PET, and MRI. In the most recent version of the IWG criteria, ${ }^{1}$ CSF $A \beta$, tau, and amyloid PET are regarded as pathophysiologic biomarkers of $\mathrm{AD}$ while FDG-PET and MRI are considered topographic downstream biomarkers. Biomarker support for $\mathrm{AD}$ pathophysiology consists of a positive amyloid PET scan or both depressed $\mathrm{A} \beta_{42}$ and elevated $\mathrm{t}$-tau or $\mathrm{p}$-tau in CSF. In the NIA-AA criteria (2011), separate guidelines were outlined for 3 clinical phasespreclinical, MCI, and $\mathrm{AD}$ dementia. ${ }^{3-6}$ The NIA-AA preclinical $\mathrm{AD}$ criteria were predicated on the concept that $\mathrm{AD}$ biomarkers follow a specific temporal ordering where $\beta$-amyloidosis occurs before tau-related neurodegeneration, which in turn is the proximate correlate of clinical symptoms. By contrast, NIA-AA criteria for $\mathrm{MCI}$ and $\mathrm{AD}$ dementia attribute equal diagnostic weight to all $\mathrm{AD}$ biomarkers included in the criteria.

Tables 1 to 3 outline how the $\mathrm{A} / \mathrm{T} / \mathrm{N}$ system maps onto these 2 existing diagnostic classification systems. Conceptual differences both between and within these sets of diagnostic criteria are evident. For example, a clinically asymptomatic individual with a positive CSF $A \beta_{42}$ and negative CSF tau profile is labeled preclinical AD stage 1 by the NIA-AA criteria but is classified as not being in the $\mathrm{AD}$ pathway by IWG. A clinically asymptomatic individual with positive CSF $A \beta_{42}$ and tau is labeled preclinical $A D$ stage 2 by the NIA-AA criteria and as "asymptomatic at risk for $\mathrm{AD}$ " by IWG. Disagreement in how these different diagnostic criteria treat biomarkers creates uncertainty for 


\begin{tabular}{|c|c|c|}
\hline Table 3 & \multicolumn{2}{|c|}{ Individuals who meet clinical criteria for probable $A D$ dementia } \\
\hline$A / T / N$ score & NIA-AA classification & 2014 IWG classification \\
\hline $\mathrm{A}-/ \mathrm{T}-/ \mathrm{N}-$ & Dementia, unlikely due to $A D$ & Not defined \\
\hline $\mathrm{A}+/ \mathrm{T}-/ \mathrm{N}-$ & $\begin{array}{l}\text { Intermediate likelihood; probable AD } \\
\text { dementia; based on clinical criteriaa }\end{array}$ & $\begin{array}{l}\text { Typical AD (if A+ established } \\
\text { by amyloid PET) }\end{array}$ \\
\hline $\mathrm{A}+/ \mathrm{T}+/ \mathrm{N}-$ & $\begin{array}{l}\text { High likelihood probable AD dementia; } \\
\text { based on clinical criteria }\end{array}$ & Typical AD \\
\hline $\mathrm{A}+/ \mathrm{T}-/ \mathrm{N}+$ & $\begin{array}{l}\text { High likelihood; probable AD dementia; } \\
\text { based on clinical criteria }\end{array}$ & $\begin{array}{l}\text { Typical AD (if A+ established } \\
\text { by amyloid PET) }\end{array}$ \\
\hline $\mathrm{A}+/ \mathrm{T}+/ \mathrm{N}+$ & High likelihood AD pathophysiology & Typical AD \\
\hline $\mathrm{A}-/ \mathrm{T}+/ \mathrm{N}-$ & $\begin{array}{l}\text { Probable AD dementia; based on } \\
\text { clinical criteria }\end{array}$ & Not defined \\
\hline $\mathrm{A}-/ \mathrm{T}-/ \mathrm{N}+$ & $\begin{array}{l}\text { Intermediate likelihood; probable } \\
\text { AD dementia; based on clinical criteria }{ }^{a}\end{array}$ & Not defined \\
\hline $\mathrm{A}-/ \mathrm{T}+/ \mathrm{N}+$ & $\begin{array}{l}\text { Intermediate likelihood; probable } \\
\text { AD dementia; based on clinical criteria }\end{array}$ & Not defined \\
\hline
\end{tabular}

Abbreviations: $A D=$ Alzheimer disease; IWG $=$ International Working Group; NIA-AA = National Institute on Aging-Alzheimer's Association.

a In the event of conflicting results, biomarkers are regarded as "uninformative" and therefore do not alter the individual's diagnostic classification based on clinical assessment alone.

investigators, regulators, and pharmaceutical companies designing trials. Thus, there is a need for a unifying conceptual approach to biomarkers used in $\mathrm{AD}$ research.

We recognize that the $\mathrm{A} / \mathrm{T} / \mathrm{N}$ biomarker system will almost always be used in conjunction with a complementary system to classify clinical impairment. By taking an unbiased descriptive approach and avoiding syndromic or disease labels, the $\mathrm{A} / \mathrm{T} / \mathrm{N}$ system can be used in any set of diagnostic criteria that exist currently or are developed in the future. In addition, the $\mathrm{A} / \mathrm{T} / \mathrm{N}$ system includes all individuals in any population and thus is suited to cognitive aging research where $\mathrm{AD}$ constitutes only part of the etiologic landscape. We leave it to expert panels such as the IWG and NIA-AA to decide what disease or syndromic labels (i.e., $\mathrm{AD}$, not $\mathrm{AD}, \mathrm{SNAP}$, preclinical $\mathrm{AD}$, at risk of $\mathrm{AD}, \mathrm{MCI}$ due to $\mathrm{AD}$, prodromal $\mathrm{AD}$, etc.) should apply to individuals with varying clinical presentations who are classified into different biomarker states by this system.

Finally, while we anticipate $\mathrm{N}$ and $\mathrm{T}$ will often concur, i.e., either both will be positive or both negative, this will not always be the case and informative profiles will be identified that are not captured by either the NIA-AA or the IWG system. For example, an $\mathrm{A}-\mathrm{T}-\mathrm{N}+$ profile would be expected with pathologies such as ischemic cerebrovascular disease or hippocampal sclerosis whereas an $\mathrm{A}-\mathrm{T}+\mathrm{N}+$ profile would be expected with PART (primary agerelated tauopathy). ${ }^{44} \mathrm{An} \mathrm{A}+\mathrm{T}-\mathrm{N}+$ profile might indicate an individual in the earliest stage of preclinical $\mathrm{AD}$ (accounting for the $\mathrm{A}+\mathrm{T}-$ status) who also has a non-AD pathology such as hippocampal sclerosis (accounting for the $\mathrm{N}+$ status). Other informative profiles will emerge as the $A / T / N$ system is applied empirically.

\section{AUTHOR CONTRIBUTIONS}

Dr. Jack: study concept and design and critical revision of the manuscript for important intellectual content. Dr. Bennett: critical revision of the manuscript for important intellectual content. Dr. Blennow: critical revision of the manuscript for important intellectual content. Dr. Carrillo: critical revision of the manuscript for important intellectual content. Dr. Feldman: critical revision of the manuscript for important intellectual content. Dr. Frisoni: critical revision of the manuscript for important intellectual content. Dr. Hampel: critical revision of the manuscript for important intellectual content. Dr. Jagust: critical revision of the manuscript for important intellectual content. Dr. Johnson: critical revision of the manuscript for important intellectual content. Dr. Knopman: critical revision of the manuscript for important intellectual content. Dr. Petersen: critical revision of the manuscript for important intellectual content. Dr. Scheltens: critical revision of the manuscript for important intellectual content. Dr. Sperling: critical revision of the manuscript for important intellectual content. Dr. Dubois: critical revision of the manuscript for important intellectual content.

\section{STUDY FUNDING}

No targeted funding reported.

\section{DISCLOSURE}

C. Jack has provided consulting services for Eli Lilly Co. He receives research funding from the NIH (R01 AG011378, U01 HL096917, U01 AG024904, RO1 AG041851, R01 AG037551, R01 AG043392, U01 AG006786) and the Alexander Family Alzheimer's Disease Research Professorship of the Mayo Foundation. D. Bennett reports no disclosures relevant to the manuscript. K. Blennow has served as a consultant for Eli Lilly, Novartis, Roche Diagnostics, and Sanofi-Aventis and on advisory boards for Amgen and IBL International, and has given lectures for Fujirebio Europe and Lundbeck. Dr. Blennow's research team has received grants for collaborative research projects from Eli Lilly and Roche Diagnostics. M. Carrillo is a full time employee of the Alzheimer's Association. H. Feldman reports no disclosures relevant to the manuscript. G. Frisoni has served on advisory boards for Lilly, BMS, Bayer, Lundbeck, Elan, AstraZeneca, Pfizer, TauRx, Wyeth, GE, Baxter. He is a member of the editorial boards of Lancet Neurology, Aging Clinical \& Experimental Research, Alzheimer's Diseases \& Associated Disorders, and Neurodegenerative Diseases. He is imaging section editor of Neurobiology of Aging. Dr. Frisoni has received grants from Wyeth International, Lilly International, Lundbeck Italia, GE International, Avid/Lilly, Roche, Piramal, and the Alzheimer's Association. Research of industrial interest has touched: memantine, PET amyloid ligands, diagnostic and tracking Alzheimer's biomarkers. Lecture fees when speaking at the invitation of a commercial sponsor (in the past 2 years): Lundbeck, Piramal, and GE. H. Hampel serves as senior associate editor for the journal Alzheimer's \& Dementia; he is a scientific advisor/consultant for Axovant, Anavex, Eli Lilly and Company, GE Healthcare, Cytox, Jung Diagnostics, Roche, Biogen, Takeda-Zinfandel, Oryzon; and receives research support from the Alzheimer Foundation (Paris), Pierre and Marie Curie University, Pfizer, Avid; and has (partly pending) patent applications, but receives no royalties. W. Jagust is a consultant to BioClinica, Banner Alzheimer's Institute-Genentech, and Novartis. K. Johnson has consulted for Novartis, AbbVie, Janssen, GEHC, Avid/Lilly, Piramal, Roche, and Isis Pharmaceuticals, is an investigator in clinical trials sponsored by Biogen, Merck, Janssen, Eisai, Navidea, Avid/Lilly, and receives research support from the NIH, Fidelity Biosciences, and the Alzheimer's Association. D. Knopman serves as deputy editor for Neurology ${ }^{\circledR}$; serves on a data safety monitoring board for Lundbeck Pharmaceuticals and for the DIAN Study; is an investigator in clinical trials sponsored by TauRX Pharmaceuticals, Lilly Pharmaceuticals, and the Alzheimer's Disease Cooperative Study; and receives research support from the NIH. R. Petersen is the chair of the data monitoring committee for Pfizer, Inc., and Janssen Alzheimer Immunotherapy, consultant for Hoffmann-La Roche, Inc., Merck, Inc., Genentech, Inc., Biogen, Inc., and Eli Lilly \& Co. He receives royalties from Oxford University Press for Mild Cognitive Impairment. P. Scheltens has received grant support (for the institution) from 
GE Healthcare, Danone Research, Piramal, and Merck. In the past 2 years he has received consultancy/speaker fees (paid to the institution) from Lilly, GE Healthcare, Novartis, Forum, Sanofi, Nutricia, Probiodrug, and EIP Pharma. R. Sperling has been a consultant for Janssen Eisai, Lundbeck, Isis, Boehringer Ingelheim, Roche, and Genentech; and receives research support from the Alzheimer's Association, Fidelity Biosciences, Janssen, BrightFocus Foundation, and the National Institute on Aging. B. Dubois has received consulting fees from Eli Lilly and Pfizer grant support from industry in 2012. Go to Neurology.org for full disclosures.

Received December 16, 2015. Accepted in final form March 16, 2016.

\section{REFERENCES}

1. Dubois B, Feldman HH, Jacova C, et al. Advancing research diagnostic criteria for Alzheimer's disease: the IWG-2 criteria. Lancet Neurol 2014;13:614-629.

2. Dubois B, Feldman HH, Jacova C, et al. Research criteria for the diagnosis of Alzheimer's disease: revising the NINCDSADRDA criteria. Lancet Neurol 2007;6:734-746.

3. Sperling RA, Aisen PS, Beckett LA, et al. Toward defining the preclinical stages of Alzheimer's disease: recommendations from the National Institute on Aging-Alzheimer's Association workgroups on diagnostic guidelines for Alzheimer's disease. Alzheimers Dement 2011;7:280-292.

4. Albert MS, DeKosky ST, Dickson D, et al. The diagnosis of mild cognitive impairment due to Alzheimer's disease: recommendations from the National Institute on Aging and Alzheimer's Association Workgroup. Alzheimers Dement 2011;7:270-279.

5. McKhann GM, Knopman DS, Chertkow H, et al. The diagnosis of dementia due to Alzheimer's disease: recommendations from the National Institute on Aging and the Alzheimer's Association Workgroup. Alzheimers Dement 2011;7:263-269.

6. Jack CR Jr, Albert MS, Knopman DS, et al. Introduction to the recommendations from the National Institute on Aging-Alzheimer's Association workgroups on diagnostic guidelines for Alzheimer's disease. Alzheimers Dement 2011;7:257-262.

7. Hampel H, Frank R, Broich K, et al. Biomarkers for Alzheimer's disease: academic, industry and regulatory perspectives. Nat Rev Drug Discov 2010;9:560-574.

8. Villemagne VL, Fodero-Tavoletti MT, Masters CL, Rowe CC. Tau imaging: early progress and future directions. Lancet Neurol 2015;14:114-124.

9. Marquie M, Normandin MD, Vanderburg CR, et al. Validating novel tau positron emission tomography tracer [F-18]AV-1451 (T807) on postmortem brain tissue. Ann Neurol 2015;78:787-800.

10. Johnson KA, Shultz A, Betensky RA, et al. Tau positron emission tomographic imaging in aging and early Alzheimer's disease. Ann Neurol 2016;79:110-119.

11. Scholl M, Lockhart SN, Schonhaut DR, et al. PET Imaging of tau deposition in the aging human brain. Neuron 2016;89:971-982.

12. Braak H, Thal DR, Ghebremedhin E, Del Tredici K. Stages of the pathologic process in Alzheimer disease: age categories from 1 to 100 years. J Neuropathol Exp Neurol 2011;70:960-969.

13. Duyckaerts C, Braak H, Brion JP, et al. PART is part of Alzheimer disease. Acta Neuropathol 2015;129:749-756.

14. Duyckaerts C. Tau pathology in children and young adults: can you still be unconditionally baptist?. Acta Neuropathol 2011;121:145-147.
15. Jack CR Jr, Holtzman DM. Biomarker modeling of Alzheimer's disease. Neuron 2013;80:1347-1358.

16. Chetelat G. Alzheimer disease: Abeta-independent processes-rethinking preclinical AD. Nat Rev Neurol 2013;9:123-124.

17. Small SA, Duff K. Linking Abeta and tau in late-onset Alzheimer's disease: a dual pathway hypothesis. Neuron 2008;60:534-542.

18. Dubois B, Feldman HH, Jacova C, et al. Revising the definition of Alzheimer's disease: a new lexicon. Lancet Neurol 2010;9:1118-1127.

19. Vos SJ, Verhey F, Frolich L, et al. Prevalence and prognosis of Alzheimer's disease at the mild cognitive impairment stage. Brain 2015;138:1327-1338.

20. Schneider JA, Arvanitakis Z, Leurgans SE, Bennett DA. The neuropathology of probable Alzheimer disease and mild cognitive impairment. Ann Neurol 2009;66:200-208.

21. Jack CR Jr, Knopman DS, Weigand SD, et al. An operational approach to NIA-AA criteria for preclinical Alzheimer's disease. Ann Neurol 2012;71:765-775.

22. Klunk WE, Engler H, Nordberg A, et al. Imaging brain amyloid in Alzheimer's disease with Pittsburgh compound-B. Ann Neurol 2004;55:306-319.

23. Fagan AM, Roe CM, Xiong C, Mintun MA, Morris JC, Holtzman DM. Cerebrospinal fluid tau/beta-amyloid(42) ratio as a prediction of cognitive decline in nondemented older adults. Arch Neurol 2007;64:343-349.

24. Mattsson N, Zetterberg H, Hansson O, et al. CSF biomarkers and incipient Alzheimer disease in patients with mild cognitive impairment. JAMA 2009;302:385-393.

25. Visser PJ, Verhey F, Knol DL, et al. Prevalence and prognostic value of CSF markers of Alzheimer's disease pathology in patients with subjective cognitive impairment or mild cognitive impairment in the DESCRIPA Study: a prospective cohort study. Lancet Neurol 2009;8:619-627.

26. Buerger K, Ewers M, Pirttila T, et al. CSF phosphorylated tau protein correlates with neocortical neurofibrillary pathology in Alzheimer's disease. Brain 2006;129:30353041.

27. Besson FL, La Joie R, Doeuvre L, et al. Cognitive and brain profiles associated with current neuroimaging biomarkers of preclinical Alzheimer's disease. J Neurosci 2015;35:1040210411.

28. Jagust WJ, Landau SM, Shaw LM, et al. Relationships between biomarkers in aging and dementia. Neurology 2009;73:1193-1199.

29. Strozyk D, Blennow K, White LR, Launer LJ. CSF Abeta 42 levels correlate with amyloid-neuropathology in a population-based autopsy study. Neurology 2003;60:652656.

30. Tapiola T, Alafuzoff I, Herukka SK, et al. Cerebrospinal fluid \{beta\}-amyloid 42 and tau proteins as biomarkers of Alzheimer-type pathologic changes in the brain. Arch Neurol 2009;66:382-389.

31. Ikonomovic MD, Klunk WE, Abrahamson EE, et al. Postmortem correlates of in vivo PiB-PET amyloid imaging in a typical case of Alzheimer's disease. Brain 2008;131: 1630-1645.

32. Hong YT, Veenith T, Dewar D, et al. Amyloid imaging with carbon 11-labeled Pittsburgh compound B for traumatic brain injury. JAMA Neurol 2014;71:23-31.

33. Krut JJ, Zetterberg H, Blennow K, et al. Cerebrospinal fluid Alzheimer's biomarker profiles in CNS infections. J Neurol 2013;260:620-626. 
34. Holmberg B, Johnels B, Blennow K, Rosengren L. Cerebrospinal fluid Abeta42 is reduced in multiple system atrophy but normal in Parkinson's disease and progressive supranuclear palsy. Mov Disord 2003;18:186-190.

35. Blennow K, Wallin A, Agren H, Spenger C, Siegfried J, Vanmechelen E. Tau protein in cerebrospinal fluid: a biochemical marker for axonal degeneration in Alzheimer disease? Mol Chem Neuropathol 1995;26:231-245.

36. Olsson A, Vanderstichele H, Andreasen N, et al. Simultaneous measurement of beta-amyloid(1-42), total tau, and phosphorylated tau (Thr181) in cerebrospinal fluid by the xMAP technology. Clin Chem 2005;51:336-345.

37. Hall S, Ohrfelt A, Constantinescu R, et al. Accuracy of a panel of 5 cerebrospinal fluid biomarkers in the differential diagnosis of patients with dementia and/or parkinsonian disorders. Arch Neurol 2012;69:1445-1452.

38. Hesse C, Rosengren L, Andreasen N, et al. Transient increase in total tau but not phospho-tau in human cerebrospinal fluid after acute stroke. Neurosci Lett 2001;297:187-190

39. Ost M, Nylen K, Csajbok L, et al. Initial CSF total tau correlates with 1-year outcome in patients with traumatic brain injury. Neurology 2006;67:1600-1604.

40. Skillback T, Rosen C, Asztely F, Mattsson N, Blennow K, Zetterberg H. Diagnostic performance of cerebrospinal fluid total tau and phosphorylated tau in CreutzfeldtJakob disease: results from the Swedish Mortality Registry. JAMA Neurol 2014;71:476-483.

41. Buerger K, Otto M, Teipel SJ, et al. Dissociation between CSF total tau and tau protein phosphorylated at threonine 231 in Creutzfeldt-Jakob disease. Neurobiol Aging 2006; $27: 10-15$

42. Blennow K, Hampel H. CSF markers for incipient Alzheimer's disease. Lancet Neurol 2003;2:605-613.

43. Fotuhi M, Do D, Jack C. Modifiable factors that alter the size of the hippocampus with ageing. Nat Rev Neurol 2012;8:189-202.

44. Crary JF, Trojanowski JQ, Schneider JA, et al. Primary agerelated tauopathy (PART): a common pathology associated with human aging. Acta Neuropathol 2014;128:755-766.

45. Josephs KA, Duffy JR, Fossett TR, et al. Fluorodeoxyglucose F18 positron emission tomography in progressive apraxia of speech and primary progressive aphasia variants. Arch Neurol 2010;67:596-605.

46. Wirth M, Villeneuve S, Haase CM, et al. Associations between Alzheimer disease biomarkers, neurodegeneration, and cognition in cognitively normal older people. JAMA Neurol 2013;70:1512-1519.
47. Rabinovici GD, Jagust WJ, Furst AJ, et al. Abeta amyloid and glucose metabolism in three variants of primary progressive aphasia. Ann Neurol 2008;64:388-401.

48. Alexopoulos P, Kriett L, Haller B, et al. Limited agreement between biomarkers of neuronal injury at different stages of Alzheimer's disease. Alzheimers Dement 2014;10:684-689.

49. De Meyer G, Shapiro F, Vanderstichele H, et al. Diagnosis-independent Alzheimer disease biomarker signature in cognitively normal elderly people. Arch Neurol 2010;67: 949-956.

50. Whitworth JA. 2003 World Health Organization (WHO)/ International Society of hypertension (ISH) statement on management of hypertension. J Hypertens 2003;21:1983-1992.

51. Murray ME, Lowe VJ, Graff-Radford NR, et al. Clinicopathologic and 11C-Pittsburgh compound B implications of Thal amyloid phase across the Alzheimer's disease spectrum. Brain 2015;138:1370-1381.

52. Thal DR, Beach TG, Zanette M, et al. [(18)F]flutemetamol amyloid positron emission tomography in preclinical and symptomatic Alzheimer's disease: specific detection of advanced phases of amyloid-beta pathology. Alzheimers Dement 2015;11:975-985.

53. Wright JT Jr, Williamson JD, Whelton PK, et al. A randomized trial of intensive versus standard blood-pressure control. N Engl J Med 2015;373:2103-2116.

54. Grasbeck R. The evolution of the reference value concept. Clin Chem Lab Med 2004;42:692-697.

55. Knopman DS, Jack CR Jr, Wiste HJ, et al. Short-term clinical outcomes for stages of NIA-AA preclinical Alzheimer disease. Neurology 2012;78:1576-1582.

56. Klunk WE, Koeppe RA, Price JC, et al. The Centiloid Project: standardizing quantitative amyloid plaque estimation by PET. Alzheimers Dement 2015;11:1-15.

57. Whitwell JL, Josephs KA, Murray ME, et al. MRI correlates of neurofibrillary tangle pathology at autopsy: a voxelbased morphometry study. Neurology 2008;71:743-749.

58. Hampel H, Schneider LS, Giacobini E, et al. Advances in the therapy of Alzheimer's disease: targeting amyloid beta and tau and perspectives for the future. Expert Rev Neurother 2015;15:83-105.

59. Portelius E, Zetterberg H, Skillback T, et al. Cerebrospinal fluid neurogranin: relation to cognition and neurodegeneration in Alzheimer's disease. Brain 2015;138:33733385.

60. Villeneuve S, Reed BR, Madison CM, et al. Vascular risk and Abeta interact to reduce cortical thickness in $\mathrm{AD}$ vulnerable brain regions. Neurology 2014;83:40-47. 


\section{Neurology}

A/T/N: An unbiased descriptive classification scheme for Alzheimer disease biomarkers Clifford R. Jack, Jr, David A. Bennett, Kaj Blennow, et al.

Neurology 2016;87;539-547 Published Online before print July 1, 2016

DOI 10.1212/WNL.0000000000002923

This information is current as of July 1, 2016

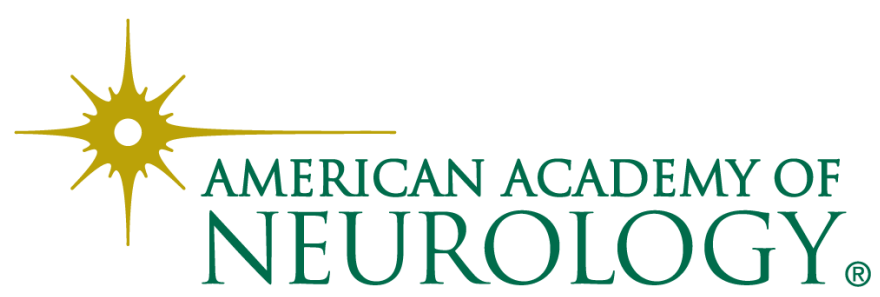




\section{Updated Information \& Services}

\section{Supplementary Material}

References

Citations

Subspecialty Collections

Permissions \& Licensing

\section{Reprints}

including high resolution figures, can be found at: http://n.neurology.org/content/87/5/539.full

Supplementary material can be found at: http://n.neurology.org/content/suppl/2016/07/01/WNL.0000000000002 923.DC1

This article cites 60 articles, 8 of which you can access for free at: http://n.neurology.org/content/87/5/539.full\#ref-list-1

This article has been cited by 44 HighWire-hosted articles: http://n.neurology.org/content/87/5/539.full\#\#otherarticles

This article, along with others on similar topics, appears in the following collection(s):

\section{All Imaging}

http://n.neurology.org/cgi/collection/all_imaging

\section{Alzheimer's disease}

http://n.neurology.org/cgi/collection/alzheimers_disease

\section{Cognitive aging}

http://n.neurology.org/cgi/collection/cognitive_aging

\section{MRI}

http://n.neurology.org/cgi/collection/mri

PET

http://n.neurology.org/cgi/collection/pet

Information about reproducing this article in parts (figures,tables) or in its entirety can be found online at:

http://www.neurology.org/about/about_the_journal\#permissions

Information about ordering reprints can be found online:

http://n.neurology.org/subscribers/advertise

Neurology ${ }^{\circledR}$ is the official journal of the American Academy of Neurology. Published continuously since 1951, it is now a weekly with 48 issues per year. Copyright @ 2016 American Academy of Neurology. All rights reserved. Print ISSN: 0028-3878. Online ISSN: 1526-632X.

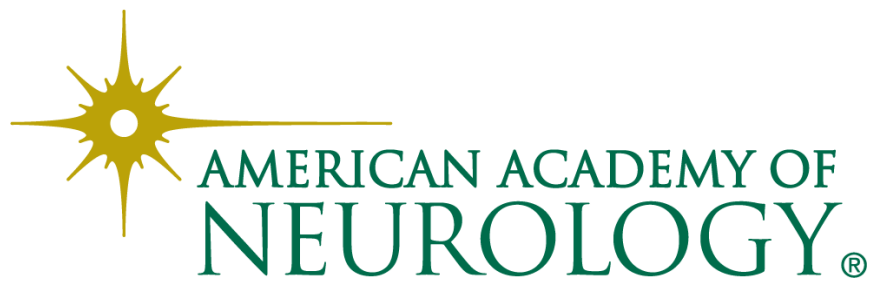

